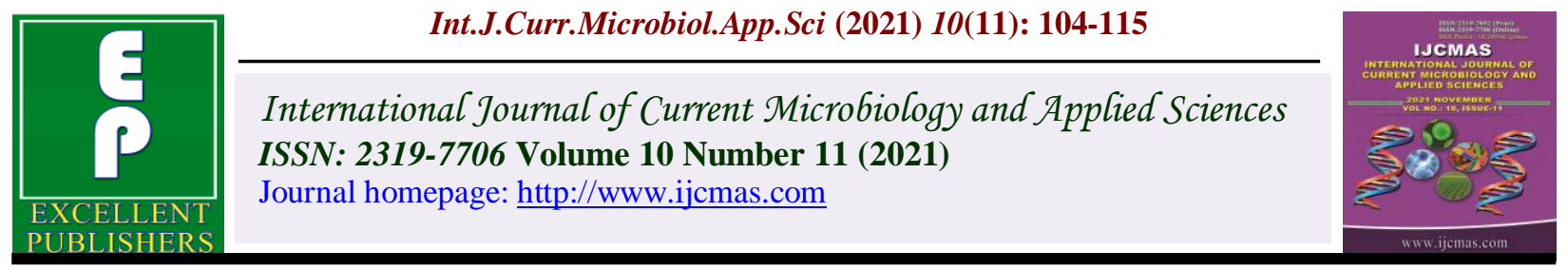

Original Research Article

https://doi.org/10.20546/ijcmas.2021.1011.014

\title{
Correlation and Path Coefficient Analysis of Yield and Yield Components in Toria [Brassica rapa (L)] Genotypes
}

\author{
Mahendra*, J. L. Salam, Nety Shraddha, D. P. Singh, Rakesh Singh and Rohit \\ Department of Genetics and Plant Breeding, S. G. College of Agriculture and Research \\ Station, Jagdalpur-404001, Chhattisgarh, India \\ *Corresponding author
}

\begin{abstract}
A B S T R A C T
Keywords

Toria, Brassica rapa, Brassica

campestris,

correlation

coefficient, path

coefficient

Article Info

Received:

05 October 2021

Accepted:

30 October 2021

Available Online:

10 November 2021 siliqua and days to $50 \%$ flowering.

\section{Introduction}

Brassica rapa originated in the high plateau regions of Iran, Iraq and Turkey (Dixon, 2007) and dispersed naturally to the Central Asia region and Western Mediterranean region. It is also known by name Brassica campestris, is a diploid crop having belonging to family Brassicaceae. Around 3500 species and 350 genera are available in this family (Rich, 1991). Brassica rapa and Brassica campestris were first characterized as two distinct species by Linnaeus, with Brassica rapa being the
\end{abstract}

This experiment was conducted at SGCARS Jagdalpur (C.G.), to assess correlation and path coefficient for 11 quantitative characters on 60 toria genotypes including one check Indira toria. The Analysis of variance revealed highly significant differences among the genotypes for all the characters considered under study. Correlation coefficient analysis revealed significant positive correlation for the traits silique per plant and seed per siliqua both at phenotypic and genotypic level with seed yield per plant. Path analysis revealed that silique per plant had highest positive direct effect towards seed yield per plant followed by siliqua length, days to maturity, harvest index, primary branches per plant, plant height, seed per

turnip type and Brassica campestris the wild weedy type. Further studies, uncovered that the two were similar species so the taxa were consolidated under the name Brassica rapa (Toxopeus et al., 1984). Brassica rapa var. Toria has chromosome number $(2 \mathrm{n}=20)$. Rapeseed contains three ecotypes viz., toria [B. rapa (L) var. toria], yellow sarson [B. rapa (L) var. yellow sarson] and brown sarson $[B$. rapa (L) var. brown sarson].

Mustard plant stature extends between 45 and $150 \mathrm{~cm}$. The roots are surface feeder and the 
root framework has constrained working profundity with a broad parallel spread. The stem is commonly covered with waxy substance. Leaves are borne sessile and are glabrous and shaggy. Flowers have 4 sepals and 4 petals of profound yellow to light yellow shading. Each flower has 6 stamens, 4 with long and 2 with short filaments while the pistil is compound. Fruit are thicker and are crosswise compressed with a beak one-third to half of the total pod length and are comprised of 2 carpels, which are isolated by a bogus septum along these lines giving 2 chambers. Seeds are either yellow or brown with a smooth seed coat. Rape is self compatible crop but cross-pollination also takes place to some extent. Indian mustard, Gobhisarson and Karan rai group are consists of self-compatible whereas, lotni type brown sarson, toria and taramira group are highly cross pollinated crop varieties. Fertilization of ovules usually results from self-pollination, although interplant outcrossing rates of $20-30 \%$ have been observed (Rakow and Woods, 1987). Bees are the primary pollen vector because the pollen is heavy and sticky and is not carried great distances by wind.

In 2016-17 area, production and productivity of the world, Mustard crop was 733.75 lakh ha, 714.50 lakh tones and $2010 \mathrm{~kg} / \mathrm{ha}$, during 2016. In India area, production and productivity was 57.62 lakh ha, 68.22 lakh tones and $1184 \mathrm{~kg} / \mathrm{ha}$. In Chhattisgarh area, production and productivity 0.43 lakh ha, 0.22 lakh tones and $517 \mathrm{~kg} / \mathrm{ha}$, respectively. In India this crop is widely cultivated in Rajasthan, Haryana, Madhya Pradesh, Uttar Pradesh, West Bengal, Gujarat, Assam, Jharkhand, Bihar and Chhattisgarh. Rajasthan solely constitutes about 25.49 lakh ha for this crop.

In Chhattisgarh area, production and productivity was 0.43 lakh ha, 0.22 lakh tonnes and $517 \mathrm{~kg} / \mathrm{ha}$, respectively (Anon., 2016).
Rapeseed contains around $42 \%$ oil. The seed and oil are utilized as fixings in the readiness of pickles and for enhancing curries and vegetables. The oil is used for human utilization all through Northern India in cooking and searing purposes. It is additionally utilized in the arrangement of hair oils and medicines. It is utilized in cleanser making in blend with mineral oils for grease. The oil cake is utilized as steers feed and compost having $5.2 \mathrm{~N}, 1.0 \mathrm{P}_{2} \mathrm{O}_{5}$ and $1.4 \mathrm{~K}_{2} \mathrm{O}$. Due to glucosinolates, mustard cake isn't appropriate for human use as it unfavourably influences protein. Green stems and leaves are a decent wellspring of green grub for dairy cattle. The leaves of youthful plants are utilized as green vegetables as they supply enough sulfur and mineral in the eating regimen. In the tanning business, mustard oil is utilized for relaxing cowhide. Mustard oil contains erucic acid in high sum and it is evacuated before use as palatable oil.

\section{Materials and Methods}

The present experiment entitled "Correlation and Path Coefficient analysis in toria [Brassica rapa (L)] Genotypes" was performed at Research cum Instructional Farm, Shaheed Gundadhoor College of Agriculture and Research Station, Kumhrawand, (Jagdalpur), Indira Gandhi Krishi Vishwavidyalaya, Raipur (Chhattisgarh) located at $\mathrm{N} 19^{\circ} 5^{\prime 3} 35^{\prime}$ longitude E 81'57'37' latitude and at an altitude ranging from 530 to 850 meters above mean sea level (MSL) with an annual rainfall $1400 \mathrm{~mm}$. The experiment was conducted during rabi2018-19 dating from 05/11/2018 to $23 / 2 / 2019$. During crop growing period temperature ranges between $34.6^{\circ} \mathrm{C}$ to $6.7^{\circ} \mathrm{C}$.

The sum of rainfall pursued during crop growing season was $52.6 \mathrm{~mm}$ whereas average relative humidity was 64.4 and bright hours were 6.8 respectively. The maximum rainfall 
(39.6 $\mathrm{mm})$ received during $3^{\text {rd }}$ week of December. The experimental material comprised of fifty nine genotypes maintained at S.G. College of Agriculture and Research Station, Jagdalpur while Indira Toria has been used as standard check variety.

Genotypes used in this experiment have been enlisted in the Table 1. Each genotype was grown in Randomized Complete Block Design in three replication with four rows of $4.5 \times 1.2$ $\mathrm{m}$ and $30 \times 10 \mathrm{~cm}$ spacing between rows and plants, during rabi season 2018-19. The standard agronomic practices were adopted for normal growth and development of crop.

The observations were recorded on five randomly selected plants per replication for each accession. The analysis of variance for different characters was carried out using the mean data through method given by Panse and Sukhatme (1967).

\section{Analysis of variance}

The analysis of variance for different characters was carried out using the mean data in order to partition the variability due to different sources by following the method given by Panse and Sukhatme (1967).

Where,

$\mathrm{SSB}=$ sum of square of block

$\mathrm{MSE}=$ mean sum of square of error

$\mathrm{MSB}=$ mean sum of square of block

TSS $=$ total sum of square

MST $=$ mean sum of square of treatment

$\mathrm{SSE}=$ sum of square of error

SST $=$ sum of square of treatment

\section{Estimation of correlation coefficient}

The correlation coefficients were worked out to determine the degree of association of a character with yield and also among the yield components. Phenotypic and genotypic correlation coefficients were computed by using the formula given by Weber and Morthy (1952).

$(r p)=\frac{\operatorname{Cov}(\mathrm{xy}) \mathrm{p} \times 100}{\sigma \mathrm{p}_{\mathrm{X}} \times \sigma \mathrm{p}_{Y}}$

$(r g)=\frac{\operatorname{Cov}(\mathrm{xy}) \mathrm{g} \times 100}{\sigma \mathrm{g}_{\mathrm{x}} \times \sigma_{\mathrm{g}}}$

Where,

$(\mathrm{rp})=$ Phenotypic correlation coefficient

$(\mathrm{rg})=$ Genotypic correlation coefficient

Cov $(x y) p=$ Phenotypic covariance between the characters ' $x$ ' and ' $y$ '

Cov (xy)g = Genotypic covariance between the characters ' $x$ ' and ' $y$ '

$\sigma \mathrm{p}_{\mathrm{X}}$ and $\sigma \mathrm{p}_{Y}=$ Phenotypic variance of the character ' $x$ ' and ' $y$ ' respectively

$\sigma \mathrm{g}_{\mathrm{X}}$ and $\sigma \mathrm{g}_{Y}=$ Genotypic variance of the character ' $x$ ' and ' $y$ ' respectively

Correlation coefficients were compared against 'r' values as given in Fisher and Yates (1963) table at (n-2) degrees of freedom at the probability levels of 0.05 and 0.01 to test their significance.

\section{Estimation of path coefficient}

The path analysis was originally developed by Wright (1921) and elaborated by Dewey and Lu (1959). Path coefficient analysis splits the 
correlation coefficients into the measures of direct and indirect effects of independent variables on dependent variable".

If a character $\mathrm{y}$ is determined by correlated characters $\mathrm{x} 1, \mathrm{x} 2$ and $\mathrm{x} 3$, a path diagram must be formulated. Thus we get a set of simultaneous equations as given below:

$r(x 1, y)=a+r(x 1, x 2) b+r(x 1, x 3) c$.

$r(x 2, y)=b+r(x 2, x 1) a+r(x 2, x 3) c$.

$r(x 3, y)=c+r(x 3, x 1) a+r(x 3, x 2) b$

Considering the three factors i.e. $\mathrm{x} 1, \mathrm{x} 2$ and $\mathrm{x} 3$, the simultaneous equations given above can be matrix notation as:

$\mathrm{rx} 1 \mathrm{y}=\mathrm{rx} 1 \mathrm{x} 1 \mathrm{r} \times 1 \mathrm{x} 1 \mathrm{r} x 1 \mathrm{x} 1 \mathrm{a}$

$r \times 2 y=r \times 2 x 1 r \times 2 \times 2 r \times 2 x 3 b$

$\mathrm{rx} 3 \mathrm{y}=\mathrm{r} \times 3 \times 1 \mathrm{r} \times 3 \times 2 \mathrm{r} \times 3 \times 3 \mathrm{c}$

Where,

rx1y = Correlation coefficient between character $\mathrm{x} 1$ and $\mathrm{y}$.

$\mathrm{rx} 2 \mathrm{y}=$ Correlation coefficient between character $\mathrm{x} 2$ and $\mathrm{y}$.

rx3y = Correlation coefficient between character $\mathrm{x} 3$ and $\mathrm{y}$.

$\mathrm{a}=$ Direct effect of character $\mathrm{x} 1$ and $\mathrm{y}$.

$\mathrm{b}=$ Direct effect of character $\mathrm{x} 2$ and $\mathrm{y}$.

$\mathrm{c}=$ Direct effect of character $\mathrm{x} 3$ and $\mathrm{y}$.

The solution for vector $\mathrm{C}$ may be obtained as follows:

$\mathrm{A}=\mathrm{B} \cdot \mathrm{C}$ or
$\mathrm{C}=\mathrm{B}-1 \mathrm{~A}$

Where,

B-1 = inverse of matrix B.

After calculating the values of path coefficient i.e. "C" vectors the residual effect can be estimated by the given formula:

$R=1-\Sigma($ rij $)$

Where,

$\mathrm{R}=$ Residual effect .

rij $=$ Correlation coefficient between $i^{\text {th }}$ character and $\mathrm{j}^{\text {th }}$ dependent variable

The results of path coefficient analysis are interpreted as per the following scale suggested by Lenka and Mishra (1973).

\section{Results and Discussion}

\section{Analysis of variance}

Analysis of variance was performed for eleven quantitative characters including yield and yield attributing traits on sixty genotypes of toria. From the analysis of variance it was observed that mean sum of squares due to genotypes were significant at $5 \%$ level of significance, thus exhibiting the presence of considerable genetic variability for all the characters considered for study. Results pertaining to analysis of variance have been presented in Table 3.This finding in confirmation with the finding of Singh et al., (2013), Tripathi et al., (2013) and Shekhawat et al., (2014).

\section{Correlation coefficient analysis}

Through correlation coefficient analysis emphasis can be given for selecting character 
which is genetically correlated with the dependent character. To know the nature and magnitude of relationship existing between the traits under study correlation coefficient was carried out at phenotypic as well as genotypic levels. Result regarding correlation among various traits had been depicted in Table 4 .

\section{Seed yield per plant $(\mathrm{g})$}

Positive significant association was shown by siliqua per plant (0.97) and seed per siliqua (0.80) whereas days to maturity $(-0.26)$ showed negative significant association at both phenotypic and genotypic level whereas primary branch per plant (-0.75) and secondary branch per plant (-0.29) showed negative significant association at genotypic level only with seed yield per plant.

\section{Days to 50 percent flowering}

This trait found significant and positively associated with secondary branches per plant (0.18) while significant and negative correlated with primary branches per plant (0.21 ) at genotypic level whereas at phenotypic level no trait was found to be significant.

\section{Days to maturity}

Negative and significant association was shown by siliqua per plant (-0.28) and seed yield per plant (-0.26) at phenotypic level.

At genotypic level siliqua per plant (-0.28), secondary branches per plant $(-0.17)$, primary branches per plant $(-0.20)$ and seed yield per plant (-0.69) showed negative significant association with days to maturity.

\section{Plant height}

Positive significant association was shown by siliqua length (0.55) whereas harvest index (0.24) was negative at phenotypic level. At genotypic level sliliqua length (0.59) and secondary branches per plant (0.19) were significant positive while, primary branches per plant (-0.43) and harvest index showed negative and significant association.

\section{Siliqua per plant}

Siliqua per plant showed positive and significant association with seed per siliqua $(0.25)$ and seed yield per plant (0.97) whereas days to maturity (-0.28) showed negative significant association at phenotypic level.

At genotypic level seed per siliqua (0.25) and seed yield per plant (0.99) showed positive and significant association while primary branches per plant (-0.42) and secondary branch per plant (-0.15) showed negative and significant association.

\section{Seed per siliqua}

Seed per siliqua showed significant and positive correlation with siliqua per plant $(0.25,0.25)$ and seed yield per plant $(0.80$, $0.91)$ at both phenotypic and genotypic level negative significant association shown by secondary branches per plant $(-0.21)$ at genotypic level only respectively.

\section{Siliqua length}

Positive and significant association was observed for plant height $(0.55,0.59)$ whereas harvest index $(-0.27,-0.30)$ showed negative and significant association at both phenotypic and genotypic level.

\section{Primary branches per plant}

Positive and significant association was shown by test weight $(0.15)$ whereas secondary branch per plant $(-0.56)$, seed yield per plant ($0.75)$, days to $50 \%$ flowering $(-0.21)$, days to maturity (-0.20), plant height $(-0.43)$ and 
siliqua per plant (-0.42) showed negative and significant association at genotypic level. At phenotypic level no trait showed significant correlation.

\section{Secondary branches per plant}

Positive and significant association was noted for plant height (0.19) whereas primary branch per plant $(-0.56)$, seed yield per plant $(-0.29)$, days to $50 \%$ flowering $(-0.18)$, days to maturity (-0.17) and siliqua per plant (-0.15) showed negative and significant association at genotypic level.

\section{Harvest index}

Positive and significant association was shown by test weight $(0.19,0.35)$ whereas plant height $(-0.24,-0.24)$ and siliqua length $(-0.27$, -30) showed negative and significant association at both phenotypic and genotypic level.

\section{Test weight}

This trait had been found significant and positively associated with primary branches per plant (0.15) and harvest index (0.35) at genotypic level whereas at phenotypic level harvest index (0.19) it is positive and significantly correlated.

It is clear that overall value of genotypic correlation was slightly higher than the values of phenotypic correlation, low phenotypic correlations can be explained due to masking or modifying effects of environment on genetic association between characters.

The experimental findings on correlation coefficient analysis has supported by earlier workers viz., Reddy (1991), Nanda et al., (1995), Uddin et al., (1995), Kumar et al., (1996), Kumar et al., (2013) and Malik et al., (2000).

\section{Path coefficient analysis}

Through correlation coefficient analysis find association between various characters but it does not tell about the type of association of independent characters with the dependent character. Path coefficient analysis splits the correlation coefficient into the measures of direct and indirect effects thus it provides information about the direct and indirect contribution of various independent characters on a dependent character. Hence it helps in determining yield contributing and thus is useful in indirect selection. The direct and indirect effects of various traits with respect to seed yield at genotypic level are presented in Table 5.

\section{Direct effects at genotypic level}

Toria germplasm under study were exposed to path analysis to estimate the direct and indirect effect of various characters towards seed yield per plant character.

Out of eleven characters included in the study, eight characters showed positive direct effect towards seed yield per plant, in which siliqua per plant (0.98) had higher positive direct effect followed by siliqua length (0.92), plant height (0.83), seed per siliqua (0.77), harvest index (0.67), days to maturity (0.66), days to $50 \%$ percent flowering $(0.65)$ and primary branch per plant (0.31) whereas negative direct effect was shown by secondary branches per plant $(-0.71)$ followed by test weight $(-0.43)$ respectively at genotypic level.

\section{Indirect effects at genotypic level}

\section{Days to 50 percent flowering}

This character had exhibited positive direct effect and positive correlation (0.11) towards trait seed yield per plant while positive indirect effect was shown through secondary 
branches per plant (0.53), siliqua per plant (0.50), days to $50 \%$ flowering (0.65) and test weight (0.08). Negative indirect effect on seed yield was through harvest index (-0.89) followed by siliqua length (-0.88), primary branch per plant (-0.66), days to maturity ($0.52)$ and seed per siliqua (-0.03).

\section{Days to maturity}

Days to maturity had negative correlation (0.69) with seed yield. It had shown negative indirect effect on seed yield through primary branches per plant $(-0.64)$, siliqua per plant ($0.44)$, harvest index $(-0.35)$, seeds per siliqua $(-0.29)$, days to $50 \%$ flowering (0.05) and test weight (-0.02) whereas days to maturity $(0.25)$, secondary branches per plant $(0.43)$ and siliqua length (0.31) had positive indirect effect.

\section{Plant height}

This trait had positive correlation (0.08) with seed yield. It had shown negative indirect effect on seed yield through secondary branches per plant (-0.84), primary branches per plant (-0.38), siliqua per plant $(-0.52)$, harvest index $(-0.14)$ and days to $50 \%$ flowering (-0.10) while positive indirect effect was shown through days to maturity (0.48), plant height (0.83), siliqua length $(0.24)$, seeds per siliqua (0.23) and test weight (0.17).

\section{Primary branches per plant}

This trait had negative correlation (-0.47) with seed yield at genotypic level. Days to 50 per cent flowering (-0.14), plant height (-0.12), siliqua per plant (-0.53), days to maturity (0.38 ) and test weight $(-0.67)$ had negative indirect effect whereas siliqua length (0.48), secondary branches per plant (0.06), primary branches per plant (0.31) and seeds per siliqua (0.38) had positive indirect effect on seed yield.

\section{Secondary branches per plant}

Trait had negative correlation (-0.29) with seed yield at genotypic level. Days to $50 \%$ flowering (-0.12), primary branches per plant $(-0.65)$, siliqua per plant $(-0.57)$, days to maturity (-0.16), secondary branch per plant ($0.71)$, seed per siliqua (-0.08) and harvest index (-0.28) had negative indirect effect whereas plant height (0.54), siliqua length (0.41) and test weight (0.04) had positive indirect effect on seed yield.

\section{Siliqua per plant}

Siliqua per plant had positive correlation (0.99) with seed yield per plant. It had shown negative indirect effect towards seed yield through days to maturity (-0.92), siliqua length $(-0.35)$, plant height $(-0.44)$ and primary branches per plant $(-0.16)$ while harvest index (0.89), secondary branches per plant (0.14), seed per siliqua (0.98), days to maturity (0.10), seed per siliqua (0.72) and test weight (0.47) had positive indirect effect.

\section{Siliqua length}

This trait had negative correlation (-0.52) with seed yield per plant. It had negative indirect impact on seed yield by four character days to $50 \%$ flowering (-0.03), secondary branches per plant (-0.29), siliqua per plant $(-0.50)$ and harvest index $(-0.58)$ whereas days to maturity (0.51), plant height (0.96), primary branches per plant (0.37), seed per siliqua (0.15) and test weight (0.41) had positive indirect impact.

\section{Seeds per siliqua}

Seeds per siliqua had positive correlation (0.91) with seed yield per plant. It had negative indirect impact on seed yield through days to 50 per cent flowering (-0.01), days to maturity (-0.07) and test weight (-0.01) while plant height (0.35), primary branches per plant (0.42), seed per siliqua (0.93), siliqua length 
(0.22), seed per siliqua (0.77), harvest index (0.77), secondary branches per plant (0.94) and test weight (0.0026) had positive indirect impact.

Table.1 Detail of the genotypes used in the experiment

\begin{tabular}{|c|c|c|c|c|c|c|c|}
\hline S.No. & Genotypes & S.No. & Genotypes & S.No. & Genotypes & S.No. & Genotypes \\
\hline $\mathbf{1}$ & GPT -22 & 16 & GPT -19 & 31 & GPT -88 & 46 & GPT -84 \\
\hline $\mathbf{2}$ & GPT -25 & 17 & GPT -51 & 32 & GPT -18 & 47 & GPT -47 \\
\hline $\mathbf{3}$ & GPT -24 & 18 & GPT- 119 & 33 & GPT -56 & 48 & GPT -31 \\
\hline $\mathbf{4}$ & GPT -90 & 19 & GPT -152 & 34 & GPT -89 & 49 & GPT -61 \\
\hline $\mathbf{5}$ & GPT -53 & 20 & GPT -26 & 35 & GPT -46 & 50 & GPT -28 \\
\hline $\mathbf{6}$ & GPT-44 & 21 & GPT -21 & 36 & GPT -118 & 51 & GPT -85 \\
\hline $\mathbf{7}$ & GPT -39 & 22 & GPT -303 & 37 & GPT -50 & 52 & GPT -20 \\
\hline $\mathbf{8}$ & GPT -43 & 23 & PT -30 & 38 & GPT -27 & 53 & GPT -57 \\
\hline $\mathbf{9}$ & GPT-113 & 24 & GPT -29 & 39 & GPT -117 & 54 & GPT -58 \\
\hline $\mathbf{1 0}$ & G0 -17 & 25 & GPT -1 & 40 & GPT -143 & 55 & GPT -49 \\
\hline $\mathbf{1 1}$ & GPT -81 & 26 & T- 9 & 41 & GPT -110 & 56 & GPT -55 \\
\hline $\mathbf{1 2}$ & GPT -23 & 27 & GPT -91 & 42 & GPT -35 & 57 & GPT -150 \\
\hline $\mathbf{1 3}$ & GPT -139 & 28 & Indira Toria & 43 & GPT -87 & 58 & GPT -99 \\
\hline $\mathbf{1 4}$ & GPT -93 & 29 & GPT -92 & 44 & GPT -111 & 59 & GPT -11 \\
\hline $\mathbf{1 5}$ & GPT -54 & 30 & GPT -71 & 45 & GPT -79 & 60 & GPT-112 \\
\hline
\end{tabular}

Table.2 Scale of direct and indirect effects.

\begin{tabular}{|c|c|}
\hline Value of direct and indirect effects & Rate/ Scale \\
\hline $\mathbf{0 . 0 0}$ to 0.09 & Negligible \\
\hline 0.10 to 0.19 & Low \\
\hline $\mathbf{0 . 2 0}$ to 0.29 & Moderate \\
\hline $\mathbf{0 . 3 0}$ to 0.99 & High \\
\hline$>1.00$ & Very high \\
\hline
\end{tabular}

Lenka and Mishra (1973)

Table.3 Analysis of variance for seed yield and seed yield attributing traits in toriagenotypes

\begin{tabular}{|c|c|c|c|c|c|c|c|c|c|c|c|c|}
\hline $\begin{array}{c}\text { Source of } \\
\text { variation }\end{array}$ & DF & DFF & DM & $\begin{array}{c}\text { PH } \\
(\mathbf{c m})\end{array}$ & SPP & SPS & $\begin{array}{c}\text { SL } \\
(\mathbf{c m})\end{array}$ & PBPP & SBPP & $\begin{array}{c}\text { HI } \\
(\boldsymbol{\%})\end{array}$ & $\begin{array}{c}\text { SYPP } \\
(\mathbf{g})\end{array}$ & $\begin{array}{c}\text { TW } \\
(\mathbf{g})\end{array}$ \\
\hline Replications & 2 & 0.26 & 2.21 & 10.78 & 8.40 & 1.14 & 0.10 & 0.45 & 0.08 & 147.54 & 109.07 & 0.01 \\
\hline Treatments & 59 & 43.33 & 35.62 & 595.89 & 2162.45 & 15.58 & 0.94 & 0.05 & 0.08 & 646.72 & 84.60 & 0.24 \\
\hline Error & 118 & 0.87 & 0.35 & 2.24 & 4.96 & 0.12 & 0.04 & 0.04 & 0.05 & 1.05 & 0.83 & 0.01 \\
\hline S. Em. \pm & & 0.53 & 0.34 & 0.86 & 3.67 & 0.20 & 0.53 & 0.12 & 0.13 & 0.59 & 0.52 & 0.06 \\
\hline CV (\%) & & 2.49 & 1.57 & 1.87 & 9.03 & 2.23 & 2.49 & 9.53 & 6.94 & 4.79 & 6.86 & 3.63 \\
\hline CD (5\%) & 1.51 & 0.96 & 2.42 & 10.29 & 0.56 & 1.51 & 1.37 & 0.37 & 1.66 & 1.47 & 0.17 \\
\hline
\end{tabular}

$\mathrm{DF}=$ Degree of freedom, DFF= Days to $50 \%$ flowering, DM= Days to maturity, PH= Plant height, SPP= Siliqua per plant, $\mathrm{SPS}=$ Seed per siliqua, $\mathrm{SL}=\mathrm{Siliqua}$ length, $\mathrm{PBPP}=$ Primary branches per plant, $\mathrm{SBPP}=$ Secondary branches per plant, HI= Harvest index, SYPP= Seed yield per plant, TW= Test weight. 
Table.4 Phenotypic (P) and Genotypic (G) correlation coefficient analysis for seed yield and its component traits in toria

\begin{tabular}{|c|c|c|c|c|c|c|c|c|c|c|c|c|}
\hline Characters & & DFF & DM & PH & SPP & SPS & SL & PBPP & SBPP & HI & TW & SYPP \\
\hline \multirow[t]{2}{*}{ DFF } & $\mathrm{P}$ & 1 & -0.74 & -0.89 & -0.06 & -0.08 & -0.31 & -0.16 & -0.72 & -0.46 & -0.22 & 0.20 \\
\hline & $\mathrm{G}$ & 1 & 0.78 & 0.92 & 0.05 & -0.01 & -0.46 & $-0.21 * *$ & $0.18 *$ & 0.47 & -0.18 & 0.11 \\
\hline \multirow[t]{2}{*}{ DM } & $\mathrm{P}$ & & & 0.07 & $-0.28 * *$ & -0.09 & 0.64 & -0.04 & -0.08 & -0.18 & 0.43 & $-0.26 * *$ \\
\hline & $\mathrm{G}$ & & & 0.72 & $-0.28 * *$ & -0.10 & 0.77 & $-0.20 * *$ & $-0.17 *$ & -0.19 & 0.46 & $-0.69 * *$ \\
\hline \multirow[t]{2}{*}{ PH } & $\mathrm{P}$ & & & & -0.15 & 0.08 & $-0.55 * *$ & -0.08 & 0.07 & $-0.24 * *$ & -0.39 & 0.09 \\
\hline & $\mathrm{G}$ & & & & -0.15 & 0.08 & $0.59 * *$ & $-0.43 * *$ & $0.19 * *$ & $-0.24 * *$ & -0.39 & 0.08 \\
\hline \multirow[t]{2}{*}{ SPP } & $\mathrm{P}$ & & & & & $0.25^{* *}$ & -0.07 & -0.12 & -0.67 & 0.15 & -0.10 & $0.97 * *$ \\
\hline & $\mathrm{G}$ & & & & & $0.25^{* *}$ & -0.08 & $-0.42 * *$ & $-0.15 * *$ & 0.14 & -0.11 & $0.99 * *$ \\
\hline \multirow[t]{2}{*}{ SPS } & $\mathrm{P}$ & & & & & & 0.47 & 0.15 & 0.13 & 0.07 & -0.04 & $0.80 * *$ \\
\hline & $\mathrm{G}$ & & & & & & 0.54 & 0.13 & $0.21 * *$ & 0.07 & -0.01 & $0.91 * *$ \\
\hline \multirow[t]{2}{*}{ SL } & $\mathrm{P}$ & & & & & & & 0.29 & -0.06 & $-0.27 * *$ & -0.17 & -0.37 \\
\hline & $\mathrm{G}$ & & & & & & & 0.19 & 0.10 & $-0.30 * *$ & -0.96 & -0.52 \\
\hline \multirow[t]{2}{*}{ PBPP } & $\mathrm{P}$ & & & & & & & & -0.12 & 0.01 & -0.19 & -0.11 \\
\hline & $\mathrm{G}$ & & & & & & & & $-0.56 * *$ & 0.09 & $0.15^{*}$ & $0.75^{* *}$ \\
\hline \multirow[t]{2}{*}{ SBPP } & $\mathrm{P}$ & & & & & & & & & 0.31 & -0.13 & 0.73 \\
\hline & $\mathrm{G}$ & & & & & & & & & -0.08 & -0.92 & $-0.29 * *$ \\
\hline \multirow[t]{2}{*}{ HI } & $\mathrm{P}$ & & & & & & & & & & $0.19 *$ & 0.62 \\
\hline & $\mathrm{G}$ & & & & & & & & & & $-0.35 * *$ & 0.62 \\
\hline \multirow[t]{2}{*}{ TW } & $\mathrm{P}$ & & & & & & & & & & & 0.94 \\
\hline & $\mathrm{G}$ & & & & & & & & & & & -0.98 \\
\hline
\end{tabular}

** Significant at $1 \%$ level of significance

* Significant at $5 \%$ level of significance

$\mathrm{DFF}=$ Days to $50 \%$ flowering, $\mathrm{DM}=$ Days to maturity, $\mathrm{PH}=$ Plant height, $\mathrm{SPP}=$ siliqua per plant, $\mathrm{SPS}=$ seed per siliqua, $\mathrm{SL}=$ siliqua length, $\mathrm{PBPP}=$ primary branches per plant, SBPP = secondary branches per plant, HI= harvest index, SYPP= Seed yield per plant, TW= Test weight. 
Table.5 Genotypic path coefficient analysis (direct and indirect) for seed yield per plant and its component traits in toria

\begin{tabular}{|c|c|c|c|c|c|c|c|c|c|c|c|}
\hline Characters & PH & PBPP & SBPP & SPP & DF & SL & SPS & TW & HI & DM & SYPP \\
\hline PH & $\mathbf{0 . 2 8}$ & -0.38 & -0.84 & -0.52 & -0.10 & 0.24 & 0.23 & 0.17 & -0.14 & 0.48 & 0.08 \\
\hline PBPP & -0.12 & $\mathbf{0 . 3 1}$ & 0.06 & -0.53 & -0.14 & 0.48 & 0.38 & -0.67 & 0.58 & -0.38 & $-0.47 * *$ \\
\hline SBPP & 0.54 & -0.65 & $\mathbf{- 0 . 7 1}$ & -0.57 & -0.12 & 0.41 & -0.08 & 0.04 & -0.28 & -0.16 & $-0.29 * *$ \\
\hline SPP & -0.44 & -0.16 & 0.14 & $\mathbf{0 . 9 8}$ & 0.10 & -0.35 & 0.72 & 0.47 & 0.89 & -0.92 & $0.99 * *$ \\
\hline DFF & -0.26 & -0.66 & 0.53 & 0.50 & $\mathbf{0 . 6 5}$ & -0.88 & -0.03 & 0.08 & -0.89 & -0.52 & 0.11 \\
\hline SL & 0.96 & 0.37 & -0.29 & -0.50 & -0.03 & $\mathbf{0 . 9 2}$ & 0.15 & 0.41 & -0.58 & 0.51 & -0.52 \\
\hline SPS & 0.35 & 0.42 & 0.94 & 0.93 & -0.01 & 0.22 & $\mathbf{0 . 7 7}$ & -0.01 & 0.77 & -0.07 & $0.91 * *$ \\
\hline TW & -0.11 & 0.48 & 0.59 & -0.32 & -0.01 & -0.39 & 0.01 & $-\mathbf{0 . 4 3}$ & 0.26 & 0.03 & -0.98 \\
\hline HI & -0.68 & 0.29 & 0.61 & 0.42 & -0.03 & -0.32 & 0.21 & -0.88 & $\mathbf{0 . 6 1}$ & -0.79 & 0.62 \\
\hline DM & 0.25 & -0.64 & 0.43 & -0.44 & -0.05 & 0.31 & -0.29 & -0.02 & -0.35 & $\mathbf{0 . 6 6}$ & $-0.69 * *$ \\
\hline
\end{tabular}

*Significant at $5 \%$ level of significance

$\mathrm{DFF}=$ Days to 50\% flowering, DM= Days to maturity, $\mathrm{PH}=$ Plant height, $\mathrm{SPP}=$ Siliqua per plant, $\mathrm{SPS}=$ Seed per siliqua, $\mathrm{SL}=\mathrm{Siliqua}$ length, $\mathrm{PBPP}=\mathrm{Primary}$ branches per plant, SBPP = Secondary branches per plant, HI= Harvest index, SYPP= Seed yield per plant, TW= Test weight. 


\section{Harvest index}

Harvest index had positive correlation (0.62) with seed yield per plant. It had negative indirect impact on seed yield through days to $50 \%$ flowering $(-0.03)$, days to maturity ($0.79)$, test weight $(-0.88)$, plant height $(-0.68)$ and siliqua length $(-0.32)$ while primary branches per plant (0.29), secondary branches per plant (0.61), siliqua per plant (0.42), seed per siliqua (0.21) and harvest index (0.61) had positive indirect impact.

\section{Test weight}

Test weight had negative correlation (-0.98) with seed yield per plant. It had negative indirect impact on seed yield through days to $50 \%$ flowering (-0.01), plant height (-0.11), siliqua length (-0.39), siliqua per plant $(-0.32)$ and test weight $(-0.43)$ while days to maturity (0.03), harvest index (0.26), seed per siliqua (0.01), secondary branches per plant $(0.59)$ and primary branch per plant (0.48) showed positive indirect impact on seed yield.

The above discussed results on direct effect of characters towards seed yield per plant at genotypic level are confirmed with the findings of earlier workers viz., Kardam et al., (2005), Gangapur et al., (2009), Yadava et al., (2018), Singh et al., (2013), Rout et al., (2018) and Shekhawat et al., (2014).This studies on path coefficient designated that days to $50 \%$ flowering, number of branches per plant, number of pods per plant, pod length and seeds per pod were the most central funders to seed yield per plant which could be taken into attention while selection.

In the present investigation, the genotypic correlation coefficients were in general, observed to be higher than that of phenotypic correlation coefficient indicating the strong inherent association for the various traits studied signifying the opportunity of effective phenotypic selection. Highest positive significant correlation with seed yield was shown by number of silique per plant followed by siliqua length and days to maturity. Thus, it can be inferred that selection based on any one of these traits either alone or in combination, would result in identifying high yielding genotypes.

This study on path coefficient designated that number of siliqua per plant and siliqua length were the direct central funders to seed yield per plant which could be taken into attention in future hybridization programs. Highest positive indirect effect was shown by plant height through siliqua length followed by silique per plant through seed per siliqua.

The results on path analysis indicated that, the siliqua per plant and siliqua length is most promising character contributing directly to seed yield and most of the other component characters associated to seed yield are contributing indirectly through this character.

\section{References}

Anonymous, 2016. Government of India. States Paper on Oilseeds.

Dewey, D. R. and Lu, K. N. 1959. A correlation and path coefficient analysis of components of crested wheat grass seed production. Agron. J., 51: 515-518.

Dixon, G. R. 2007. Vegetable brassica and related crucifers. Cambridge, Mass. CABI, :1-339.

Fisher, R. A. and Yates, F. 1963.Statistical tables for biological, agricultural and medical research.Oliver and Boyd, Edinburgh, 145149.

Gangapur, B. G., Doddabhimappa, R., Prakash, P., Salimath, M., Ravikumar, R. L.and Rao, M. S. L. 2009. Correlation and path analysis in Indian mustard (Brassica juncea L. Czern and Coss). Karnataka J. Agric. Sci., 22 (5): 971-977.

Kardam, D. K. and Singh, V. V. 2005. Correlation and path analysis in Indian mustard (Brassica juncea L.) Czern and Coss) grown 
under rainfed condition. J. Spices and Aromatic Crops, 14 (1): 56- 60.

Kumar, B., Pandey, A. and Singh, S. K. 2013.Genetic diversity for agro morphological and oil quality traits in Indian mustard (Brassica juncea L. Czern and Coss). The Bioscan,8(3): 771- 775.

Kumar, C. H. M. V., Arunachalam, V. and Rao, P. S. K. 1996. Ideotype and relationship between morpho-physiological characters and yield in Indian mustard (Brassica juncea L.). Indian J. Agric. Sci., 66(1): 14-17.

Lenka, D. and Mishra, B. 1973. Path coefficient analysis of yield in rice varieties. Indian J. Agric. Sci., (43): 376-379.

Malik, M. A., Das, M. L. and Rahman, A. 2000.Genetic variability, character association and path analysis in rapeseed. Bangladesh J. Agric. Sci., 27(1): 25-59.

Nanda, R., Bhargava, S. C. and Tomar, D. P. S. 1995. Rate and duration of siliqua and seed filling and their rotation to seed yield in Brassica species. Indian J. Agric. Sci., 64(4): 227-232.

Panse, V. G. and Sukhatme, P. V. 1967. Statistical Methods for Agricultural Research Workers. $3^{\text {rd }}$ edition, ICAR, New Delhi.

Rakow, G. and Woods, D. L. 1987. Outcrossing in rape and mustard under Saskatchewan prairies conditions. Can. J. Plant Sci., 67: $147-151$

Reddy, N. N. 1991. Correlation studies in Indian mustard (Brassica juncea L. Czern and Coss.). J. Oilseeds Res., 8(2): 248-250.

Rich, T. C. G. 1991. Crucifers of Great Britain and Ireland. Botanical Society of the British Isles, London, $: 336$.

Rout, S., Kerkhi, S. A. and Charupriya, C. 2018. Character Association and Path Analysis among Yield Components in Indian Mustard [Brassica juncea (L.) Czern and Coss]. Int.J.Curr.Microbiol.App.Sci., 7(1): 50-55.
Shekhawat, G. Jadeja C., Singh, J. and Shekhawat, R.S. 2014. Character association studies among yield and its component characters in Indian mustard (Brassica juncea L. Czern and Coss). The Biosean, 9(2): 685-688.

Singh, P., Chauhan, V. V., Meena, J. S. and Mishra, D. C. 2013. Correlation and path coefficient analysis for yield and yield components inearly generation lines of Indian mustard (Brassica juncea L.). Current Advances in Agricultural Sciences, 5(1):3740.

Toxopeus, H., Oost, E. H. and Reuling, G. 1984. Current aspects of the taxonomy of cultivated Brassica species. The use of Brassica rapa L. versus Brassica campestris L. and a proposal for a new intraspecific classification of Brassica rapa L. Crucifer Newsletter, 9:55-57.

Tripathi, N., Kumar, K. and Verma, O. P. 2013. Genetic Variability, Heritability and Genetic Advance in Indian Mustard (Brassica juncea L. Czern and Coss) for Seed Yield and it's Contributing Attributes Under Normal and Saline/Alkaline Condition. Int. J. of sci. and Res., 6-14.

Uddin, M. J., Chowdhury, M. A. Z. and Miah, M. F. U. 1995. Genetic variability, character association and path analysis in Indian mustard (Brassica juncea L.). Bangladesh Ann. Agric., 5(1): 51-52.

Weber, C. R. and Morthy, B. R. 1952.Heritable and non-heritable relationship and variability of oil content and agronomic characteristics in the $F_{2}$ generation of soybean crosses.Agro. J., 44: 202-209.

Wright, S. 1921. Correlation and causation. J. Agril. Res., 20: 557-585.

Yadav, S. and Pandey, A. 2018.Genetic diversity analysis of Indian mustard (Brassica juncea L.). International Journal of Chemical Studies, 6(5): 1722-1725.

\section{How to cite this article:}

Mahendra, J. L. Salam, Nety Shraddha, D. P. Singh, Rakesh Singh and Rohit. 2021. Correlation and Path Coefficient Analysis of Yield and Yield Components in Toria [Brassica rapa (L)] Genotypes. Int.J.Curr.Microbiol.App.Sci. 10(11): 104-115.

doi: https://doi.org/10.20546/ijcmas.2021.1011.014 